\title{
Just because you can, doesn't mean you should: The flipside of technical feasibility
}

\author{
Christoph Haller, MD
}

\author{
From the Division of Cardiovascular Surgery, Hospital for Sick Children and University of Toronto, Toronto, \\ Ontario, Canada. \\ Disclosures: Author has nothing to disclose with regard to commercial support. \\ Received for publication Oct 7, 2016; accepted for publication Oct 7, 2016; available ahead of print Nov 16, 2016 \\ Address for reprints: Christoph Haller, MD, 555 University Ave, M5G 1X8 Toronto, Ontario, Canada (E-mail: \\ christoph.haller@sickkids.ca). \\ J Thorac Cardiovasc Surg 2017;153:e37-8 \\ $0022-5223 / \$ 36.00$ \\ Copyright (C 2016 by The American Association for Thoracic Surgery \\ http://dx.doi.org/10.1016/j.jtcvs.2016.10.035
}

The anastomosis of the ascending aorta with the pulmonary artery (PA), initially described by Waterston in $1962,{ }^{1}$ is an outdated palliative shunt procedure. However, the growing population of adults with congenital heart disease and the suboptimal follow-up in this patient group ${ }^{2}$ eventually lead to encounters with patients who are experiencing the late sequelae of such an aortopulmonary shunt.

In this issue of the Journal, Kwak and colleagues ${ }^{3}$ present the unusual case of a patient with ventricular septal defect (VSD) and pulmonary stenosis who was palliated with a Waterston shunt and developed a giant right PA aneurysm. Irregular follow-up and various modifications of shunt procedures could not halt growth of the aneurysm. To reduce the risk of rupture, late corrective surgery was finally performed. Although the actual repair is neither new nor particularly complex, the scenario itself is a fortiori challenging. Especially the physiologic aspects before and after corrective surgery in the setting of a long-standing aortopulmonary shunt and hypertensive changes of the pulmonary vascular bed are worth giving thought to.

The risk of rupture of PA aneurysms is associated with pulmonary arterial hypertension $(\mathrm{PAH})^{4}$; therefore, it is reasonable to aim at reduction of PA pressure. On the other hand, patients with $\mathrm{PAH}$ that persists after corrective surgery have poorer survival compared with those with other types of PAH associated with congenital heart disease, arguing against surgical repair. ${ }^{5,6}$ This creates a dilemma that is not easily tackled. The high right PA pressure and long-standing shunt perfusion of the PAs for approximately 50 years suggest significant pulmonary vascular disease that makes successful repair unlikely. Nevertheless, the hypoplastic left PA seemed to be protected from excessive blood flow from both the Waterston shunt and the VSD. In addition, pulmonary stenosis in the setting of a VSD may have led to intrinsic right ventricular (RV) training, allowing the RV to endure higher afterload. This can explain why corrective surgery was tolerated fairly well, at least in the short term. It is also mentioned that the artificially created atrial septal defect showed left-to-right shunting

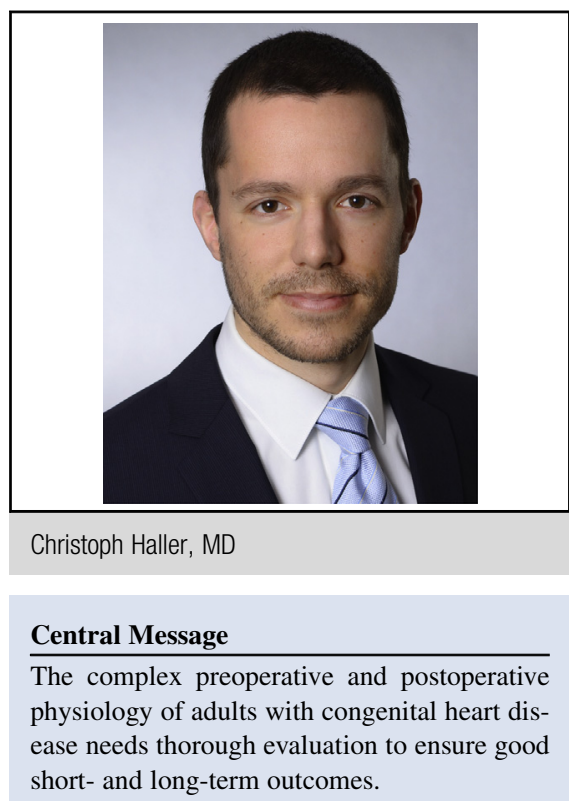

See Article page e33.

postoperatively. This is difficult to interpret, because volume unloading of the left ventricle after take-down of the PA shunts, suspected residual pulmonary hypertension, residual pulmonary valve stenosis, and a restrictive muscular $\mathrm{RV}$ give reason to expect right-to-left shunting.

Measurements of PA pressure in patients after pneumonectomy have shown that PAH is rare and relatively mild. ${ }^{7}$ Therefore, assessment of differential pulmonary blood flow by perfusion magnetic resonance imaging and detailed PA pressures and resistances would be excellent to gain better insight in this patient's postoperative physiology. It is speculative, but the right pulmonary vascular bed may not receive relevant blood flow, while the majority of pulmonary perfusion is guided to the left, counterbalancing high right-sided PA pressures. The postoperatively reduced right pulmonary vascularity supports this assumption and raises the question if primary right pneumonectomy for simultaneous resection of the aneurysm and removal of a nonperfused lung would have been preferable.

Initial improvement and good short-term outcome can obscure progressing pulmonary vascular disease and ventricular dysfunction. ${ }^{8}$ If corrective surgery in this patient can ultimately be considered successful remains to be proven. 


\section{References}

1. Waterston DJ. Treatment of Fallot's tetralogy in children under 1 year of age. Rozhls v Chir. 1962;41:181-3.

2. Wray J, Frigiola A, Bull C. Adult Congenital Heart Disease Research Network (ACoRN). Loss to specialist follow-up in congenital heart disease; out of sight, out of mind. Heart. 2013;99:485-90.

3. Kwak JG, Lee C-H, Choi ES, Kim SH. Corrective surgery for a patient with a giant right pulmonary artery developing 40 years after Waterston-Cooley shunt for pulmonary stenosis and ventricular septal defect. J Thorac Cardiovasc Surg. 2017; 153:e33-5.

4. Hull DA, Shinebourne E, Gerlis L, Nicholson AG, Sheppard MN. Rupture of pulmonary aneurysms in association with long-standing Waterston shunts. Cardiol Young. 2001;11:123-7.
5. Manes A, Palazzini M, Leci E, Bacchi Reggiani ML, Branzi A, Galiè N. Current era survival of patients with pulmonary arterial hypertension associated with congenital heart disease: a comparison between clinical subgroups. Eur Heart J. 2014;35:716-24.

6. Van Loon RLE, Roofthooft MTR, Hillege HL, ten Harkel AD, van OschGevers M, Delhaas T, et al. Pediatric pulmonary hypertension in the Netherlands: epidemiology and characterization during the period 1991 to 2005. Circulation. 2011;124:1755-64.

7. Deslauriers J, Ugalde P, Miro S, Ferland S, Bergeron S, Lacasse Y, et al. Adjustments in cardiorespiratory function after pneumonectomy: results of the pneumonectomy project. J Thorac Cardiovasc Surg. 2011;141:7-15.

8. Dimopoulos K, Wort SJ, Gatzoulis MA. Pulmonary hypertension related to congenital heart disease: a call for action. Eur Heart J. 2014;35:691-700. 